\title{
Closely linked DNA elements control the expression of the Sgs-5 glue protein gene in Drosophila
}

\author{
Eileen $M$. Shore ${ }^{1}$ and Gregory $M$. Guild \\ Department of Biology, University of Pennsylvania, Philadelphia, Pennsylvania 19104-6017 USA
}

\begin{abstract}
cis-acting sequence regions involved in the regulation of $S g s-5$ gene expression were mapped by testing DNA segments containing the Sgs- 5 RNA coding region and various amounts of adjacent sequences for the ability to express Sgs-5 RNA. Following injection of the DNA segments into Drosophila embryos, expression of the gene was assayed in the salivary glands of the injected animals after they developed to third instar larvae, these somatically transformed individuals serving as an in vivo transient expression system. The information necessary for the expression of Sgs-5 is contained within 109 bp upstream and 69 bp downstream of the transcribed region. Somatic transformation experiments also show that some feature within the limits of a 1012-bp DNA segment containing the Sgs-5 RNA coding region derived from the Sgs-5 RNA null stock CA-2 must be responsible for the lack of transcription from this allele. The only DNA sequence differences between active and null alleles, within the 1012 bp, are seven single-base-pair substitutions between -84 bp and +175 bp relative to the RNA start site. One or a combination of these sites are likely contributors to the transcriptional inactivity of the $S g s-5^{\mathrm{CA} 2}$ allele.
\end{abstract}

[Key Words: Drosophila; glue protein; Sgs-5; transformation; cis-acting elements; gene expression]

Received April 3, 1987; revised version accepted August 7, 1987.

An important function of the larval salivary gland in Drosophila melanogaster is to synthesize and extrude a mucoprotein glue that serves to attach the animal to a dry surface where it can undergo metamorphosis (Fraenkel and Brookes 1953). The salivary gland secretion (sgs) proteins are a major component of this glue and are synthesized from RNAs that are transcribed only in the salivary glands of late third instar larvae. These transcription units are located within the chromosomally dispersed salivary gland intermolt puff sites which are apparent during mid-third larval instar, the earliest stage at which the polytene chromosomes can be easily observed.

The $90 \mathrm{BC}$ intermolt puff contains the salivary gland secretion gene $S g s-5$ at 90B3-8 on the polytene chromosome map (Guild and Shore 1984). Structural analyses of the $S g s-5$ gene by DNA sequencing and RNA protection experiments have identified a transcriptional unit and putative $5^{\prime}$ cis-acting regulatory regions (Shore and Guild 1986). The primary transcript includes three exons and two small introns; the accumulated RNA is about 750 nucleotides in length including a poly(A) tail. Conceptual translation of the message reveals a protein of 163 amino acids, the first 18 of which give the amino end of the protein the hydrophobic nature typical of a signal peptide.

'Present address: Institute for Cancer Research, Fox Chase Cancer Center, Philadelphia, Pennsylvania 19111 USA.
$P$ element-mediated germ line transformation (Spradling and Rubin 1982) has been used to examine the molecular basis of expression of various Drosophila genes which, following injection into embryos, become stably integrated in the genome. Expression of injected genes also can be detected in the injected individuals, the $\mathrm{G}_{0}$ generation (Rubin and Spradling 1982, 1983; Steller and Pirrotta 1984; Haenlin et al. 1985; Preiss et al. 1985; Martin 1986), and expression of injected genes in these somatically transformed individuals can occur in a tissue- and stage-specific manner (Rubin and Spradling 1982; Martin et al. 1986). As in P element germ line transformation, somatically transformed genes are expressed in vivo. However, the time required before the gene is assayed is much shorter, days versus the weeks required to establish a stable transformed line.

We have used the somatic transformation system to analyze the regulation of the Sgs-5 gene from the Oregon-R stock $\left(S g s-5^{O R}\right)$ and show that the information necessary for its expression is contained within $109 \mathrm{bp}$ upstream and $69 \mathrm{bp}$ downstream of the gene's RNA coding region.

In addition, we present a molecular and genetic analysis of the Sgs-5CA2 allele, which does not direct the accumulation of detectable amounts of Sgs-5 RNA or SGS-5 protein (Guild and Shore 1984), and suggest that one or a combination of seven single-base-pair changes (relative to the $S g s-5^{O R}$ allele) is responsible for the RNA-negative phenotype of this allele. 


\section{Results}

The somatic transformation system

To assay Sgs-5 expression through somatic transformation, plasmid DNA containing a portion of the Sgs-5 gene region was injected into early embryos whose endogenous Sgs-5 gene copy does not allow the accumulation of detectable levels of RNA. Knowing the developmental profile of $S g s-5$ expression (Guild 1984), injected individuals were allowed to develop to the late third instar, the stage at which expression is expected to be most apparent. The salivary glands were dissected from each larva, and RNA was extracted, fractionated on agarose gels, and probed for the presence of Sgs-5 RNA. Since other glue protein genes show similar temporal specificity (Muskavitch and Hogness 1980; Wolfner 1980; Meyerowitz and Hogness 1982), we checked the developmental time at which Sgs-5 expression was assayed by probing the salivary gland RNA blots for $S g s-3$ RNA as well.

To verify the presence of injected DNA in the assayed animal, we used the Drosophila alcohol dehydrogenase $(A d h)$ gene as a marker. ADH activity resulting from an injected gene segment remains restricted to the larval tissues that normally express Adh (Ursprung et al. 1970), as has been demonstrated by histological staining of tissues from injected animals (Martin et al. 1986; our unpubl.).

Two electrophoretically distinct alleles of the $\mathrm{ADH}$ protein have been identified (Johnson and Dennison 1964) and can be utilized when injecting into $\mathrm{Adh}^{+} \mathrm{em}$ bryos. The Sgs-5- Adh $^{+}$strain (CA-2; Guild and Shore 1984) used in the experiments to be described here is homozygous for $A d h^{F}$ (fast allele). DNA containing $A d h^{S}$ (slow allele) was coinjected into CA-2 embryos with the Sgs-5 gene segment to be tested. The protein products of the two alleles are easily separated and recognized by extracting proteins from the larval carcass, electrophoresing the samples on cellulose acetate gels, and staining for ADH activity. The $A d h^{S}$ homodimer and the $A d h^{F}$ $A d h^{s}$ heterodimer forms indicate the presence and activity of the injected $A d h^{s}$ gene. This is a fairly sensitive assay, requiring only a small tissue sample. In some cases, DNA from a portion of the nonsalivary gland tissues was extracted and probed directly for the presence of injected plasmid DNA.

Sgs-5 expression was scored simply as the presence or absence of $S g s-5$ RNA on RNA blots with no emphasis on the abundance of the transcripts. Each larva assayed reflects an independent injection experiment: No two larvae received exactly the same amount of injected DNA, and the distribution of the injected DNA among various tissues may differ. For these reasons, conclusions based on quantitative evaluation of somatic transformation data must be made with caution. Some individuals were eliminated from consideration either due to lack of evidence for injected DNA or because the developmental stage assayed does not appear conducive to Sgs-5 expression.

\section{Deletion analysis of the Sgs-5 flanking regions}

Segments of genomic DNA containing the Sgs-5 coding region and various amounts of adjacent upstream and downstream sequences have been tested for $S g s-5$ expression by somatic transformation. Figure 1A shows the extent and position of these segments relative to the Sgs-5 coding region.

The largest genomic DNA segment examined is a BamHI restriction fragment that contains approximately $2.4 \mathrm{~kb}$ of DNA upstream and $0.5 \mathrm{~kb}$ downstream from the Sgs-5 RNA coding region. The plasmid paDm2459 (Fig. 1A) was coinjected into CA-2 embryos with pWX1023, a plasmid containing the $A d h^{s}$ allele. Since the Adh and Sgs-5 genes are located on different plasmids, it is unlikely that $A d h$ sequences act to influence Sgs-5 expression. Figure 2 (lanes 1-4) shows the Sgs-5 transcripts from four of the animals injected with paDm2459, as well as the Sgs-3 expression controls for those individuals. A summary of the data for all assayed individuals is found in Table 1. Of the 29 individuals assayed for expression from paDm2459, 22 were in the proper developmental stage and contained injected DNA, and 21 of those $(95 \%)$ were observed to contain Sgs-5 RNA. The $3.7-\mathrm{kb}$ BamHI fragment also was inserted into the $\mathrm{P}$ element vector $\mathrm{pPA}-2$ which contains a transcriptionally active $A d h$ gene. This alternate construct, ppDm494, was observed to express $S g s-5$ after injection into an $\mathrm{Sgs}^{-5^{-}}$; $A \mathrm{Ah}^{-}$stock, HL (data not shown), as well as when injected into the $S g s-5 \mathrm{RNA}^{-}$stock CA-2 (Fig. 1A, lanes 5-8, and Table 1).

The HindIII fragment containing the Sgs-5 RNA coding region (Fig. 1A) was examined in detail by DNA sequence analysis and RNA protection experiments (Shore and Guild 1986). This 1012-bp segment contains the entire $S g s-5$ coding region and 173 bp upstream and $69 \mathrm{bp}$ downstream from the RNA coding region. Sequences with homology to CAAT and TATA regulatory elements occur in the expected positions relative to the RNA start site (Fig. 1B). Both orientations of the restriction fragment were subcloned into the HindIII site of pBR322 (paDml687 contains the insert in the same relative orientation as paDm2459, and paDm500 has the insert in the reversed direction) and were assayed for expression as described above. Both plasmids express Sgs-5 RNA (Fig. 2A, lanes 9-16). Of the 18 animals injected with paDml687, 13 were in the correct developmental stage and contained plasmid DNA, and 12 of those $(92 \%)$ were positive for Sgs-5 RNA. Similarly, injection of paDm500 resulted in an Sgs-5 $\mathrm{RNA}^{+}$response in $90 \%$ of the appropriate animals.

Two additional DNA segments tested for Sgs-5 expression were constructed from paDm 1687 by removing a portion of $5^{\prime}$ noncoding DNA between the upstream HindIII end and a unique restriction site within the insert, either RsaI or HaeII (see Fig. 1). Both inserts are in the same relative orientation in the vector as $\mathrm{paDm} 1687$ and paDm2459. The plasmid paDm498 contains the Sgs-5 RNA coding region, $109 \mathrm{bp}$ upstream and $69 \mathrm{bp}$ downstream (Fig. 1). These sequences are sufficient for transcription of the gene (Fig. 2A, lanes 17-20). Of the 
A.

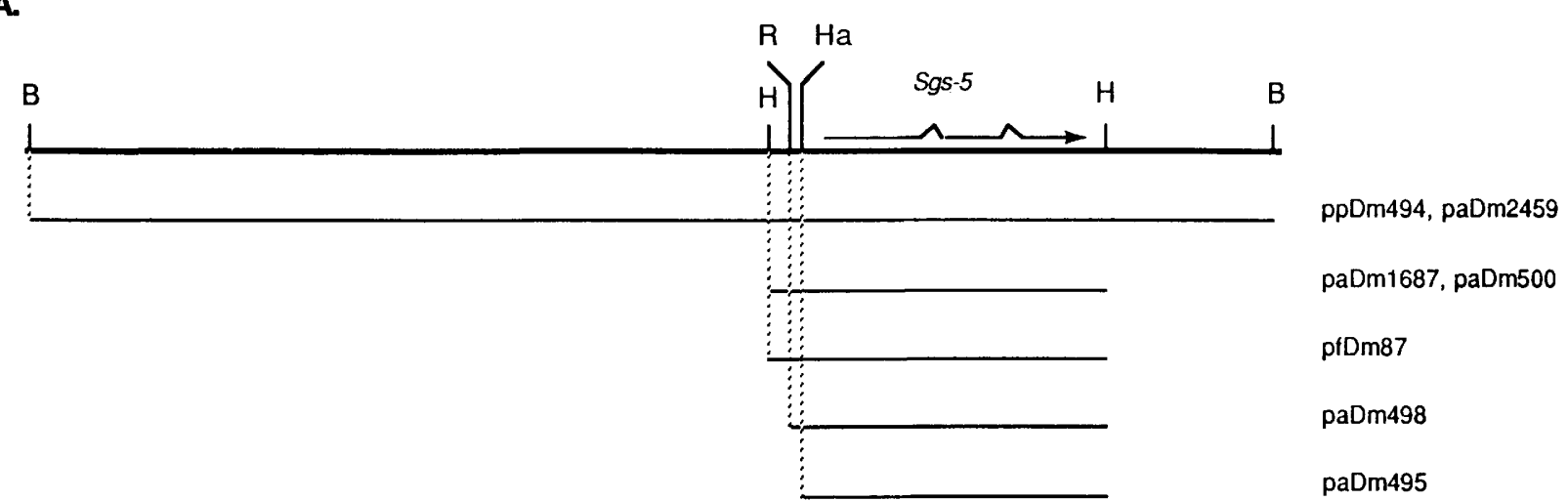

B.

$-170$

AAG CITITIITIG GAGTGGAAAA TITATGGCTG TGTTIITITG GCCAGTCAAG GTTGTTTGCG TACGTTCTGC AAACATTTTA CTITCAGATG CACTAAGTCA ATAAAGCGCT TTGCCACAAC TGCTAAAACA GTGGAGTGTA TTCAATATAA ATAGCCAAAT GAGATATTAT +1 G A gGgGACAGTTATATTCTTAGCCACTITIACGAC ATG TTC AAT ATT AAA TTG CTG CTT TTG TTA TTG GCC GTT TCG TGG TTC CAC CAT $+88$ GGA CAA GCC GTC CAG GAG ACG AAA ATC GAA GAA AAA CCA GTA TCA GAG CCT GAA ATT GAA TCC GAA ATA AAG AAC TCT ACG $+169 \quad T$ AGC GTC CCA AGT AAA TGC AAT ATT TAC TAT AGG AAC TAC CAA TGG GCT CTT CAG GAT TGT GTC TGC CGT TGT TTC CAA AAC $+250$ GAA TGC CTT ATG CAA ATC GAG AGC GAC CAG CGC AAA AAG GAG GGT AGA TCC C

Figure 1. (A) Genomic DNA segments tested by somatic transformation. The positions of restriction sites were determined by standard mapping techniques and from DNA sequence data (Shore and Guild 1986). The arrow above the restriction map represents the position of the Sgs-5 RNA coding region with the introns shown by $\wedge \mathrm{s}$. The direction of transcription is indicated, $5^{\prime} \rightarrow 3^{\prime}$. The extent of the genomic DNA segments used in the somatic transformation experiments presented here is shown below the restriction map; vertical dotted lines indicate the restriction site used to form the upstream boundary of each segment. The plasmid constructs containing a given DNA segment are listed to the right of the respective insert. The plasmid vector pBR322 was used in all cases except $\mathrm{ppDm} 494$ which used the vector pPA-2 and $\mathrm{pfDm} 87$ which used the vector $\mathrm{pBR}^{-} \mathrm{S}$. The insert in pfDm 87 was derived from CA-2 genomic DNA; all other insert fragments are from Oregon- $\mathrm{R}$ genomic DNA. The plasmids ppDm494 and paDm2459 each contain the Sgs-5 coding region within the 3.7-kb BamHI fragment; paDm1687, paDm500, and pfDm87 contain a 1012-bp insert; paDm498 contains a 948-bp insert; paDm495 contains a 900-bp insert. The plasmids paDm2459, paDml687, pfDm87, paDm498, and paDm495 contain the insert fragment in the same relative orientation; paDm500 contains its insert in the reverse orientation. (B) BamHI; (H) HindIII; (R) RsaI; (Ha) HaeII). (B) DNA sequence near the Sgs-5 RNA start site. A portion of the DNA sequence that has been determined (474/1012 bp) from the Oregon-R Sgs-5 region (Shore and Guild 1986) is shown, from the HindIII site that is the upstream boundary of the paDm 1687 insert to the end of exon 1 . The solid line above the sequence indicates the approximate position of the sequence relative to the map in $A$. The sequences upstream from the RNA coding region are shown in groups of 10 nucleotides; the protein coding region is shown in triplets. The underlined bases are the HindIII site at $-171 \mathrm{bp}$, the RsaI site at - $108 \mathrm{bp}$, and the HaeII site at $-61 \mathrm{bp}$. The boxed sites are the CAAT sequence $(-75)$ and the TATA box $(-25) .+1$ is the RNA start site, and the first ATG begins at +34 . The sequence determined from CA-2 genomic DNA is identical to the Oregon-R-derived sequence except at seven positions. The bases that occur at these sites in CA-2 DNA are indicated above the sequence. Four of these differences occur in the protein coding region, all within exon 1; three are upstream of the RNA start site. The base pair substitution at -65 removes the HaeII recognition sequence from CA-2.

36 animals assayed for Sgs-5 RNA, 29 were in the proper developmental stage and contained injected DNA, and 28 of those $(96 \%)$ synthesized Sgs-5 transcripts (Table 1).

The Sgs-5-containing insert of paDm495 begins at the HaeII site shown in Figure 1, retaining only 61 bp upstream from the RNA start site. This segment does not contain the identified CAAT sequence (Fig. 1B). Removal of these $48 \mathrm{bp}$ from the upstream end of the paDm498 insert segment to form the paDm495 insert segment (Fig. 1) is correlated with the loss, or at least severe reduction, of Sgs-5 expression (Fig. 2A, lanes
21-24). Of the 49 individuals injected with paDm495 that were assayed for Sgs-5 RNA, 41 were in the proper developmental stage and contained injected DNA; none directed detectable accumulation of Sgs-5 RNA (Table 1). Experiments using some of the injected animals (not shown) directly demonstrated the presence of the injected paDm495 DNA by DNA blot analysis in addition to the $\mathrm{ADH}$ assay. Absence of the plasmid DNA is correlated with a lack of $\mathrm{Adh}^{S}$ expression.

We wish to note that on some very long autoradiographic exposures of Sgs-5-probed RNA blots derived from 


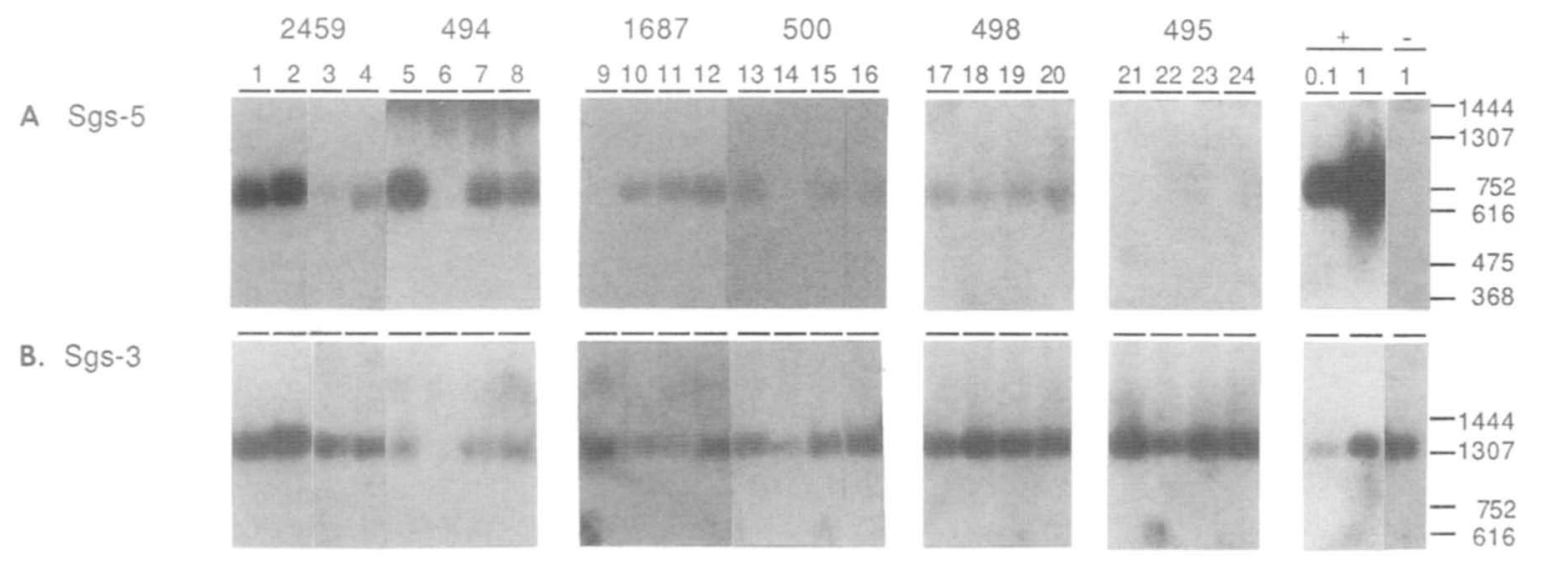

Figure 2. Examples of gene expression assays in somatically transformed animals. Vertical columns show examples of individuals injected with the plasmid indicated at the top of the column. Refer to Fig. 1 for the insert contained in each plasmid. RNA from the third-instar larval salivary glands of individual injected animals was extracted and electrophoresed through $1.4 \%$ agarose gels containing formaldehyde, blotted to nitrocellulose, then probed with ${ }^{32}$ P-labeled RNA synthesized from pnDm384 to detect $S g s-5$ transcripts $(A)$. Each RNA filter was subsequently washed to remove the Sgs-5 probe and reprobed for endogenous Sgs-3 transcripts $(B)$ with nick-translated aDm2023. Results from injected individuals are in lanes 1-24. The rightmost column shows control lanes: 1.0 and 0.1 larval equivalents from the Oregon-R Sgs-5 RNA ${ }^{+}$stock $(+\mid$and 1.0 larval equivalent from the CA-2 Sgs-5 RNA- stock $(-)$ were probed for Sgs-5 RNA (A) or Sgs-3 (B) RNA. Note: The autoradiographic exposure of the control lanes probed for $S g s-3$ RNA is equivalent to the exposure of the sample lanes probed for Sgs-3 RNA; the exposure of the positive control lanes $|+|$ probed for $S g s-5$ RNA is about 3.5-fold less than the exposure of the sample lanes probed for Sgs-5 RNA, whereas the negative control lane (-) probed for $S g s-5$ RNA is at the same exposure as the samples. The positions of size markers (M) for RNA blots are also indicated.

paDm495-injected animals we see faint hybridization signals at the position of Sgs-5 RNA. This occurs in 14 of 49 samples $(28 \%)$. There is no consistent correlation between these signals and presence or amount of $\mathrm{Adh}^{S}$, paDm495 DNA, or Sgs-3 RNA, and these signals are much lower in intensity than those scored as positive Sgs-5 RNA signals in other injection experiments. These signals could represent extremely low levels of $S g s-5$ transcripts but more likely are due to nonspecific hybridization.

These experiments demonstrate that the cis-acting information required for Sgs-5 transcription occurs within $109 \mathrm{bp}$ upstream and $69 \mathrm{bp}$ downstream of the $S g s-5$ RNA coding region. Elimination of the sequences between 61 and 109 bp upstream from the $S g s-5$ RNA start site results in the loss, or at least the severe reduction, of transcription.

\section{Tissue specificity}

Sgs-5 RNA normally accumulates only in third larval instar salivary gland cells (Guild 1984). To determine which portions of the Sgs-5 gene region are required to confer tissue specificity, animals were somatically transformed with either paDm2459 or paDm498 (Fig. 1A). As described above, DNA from these Sgs-5-containing plasmids was coinjected with the $A d h^{s}$-containing plasmid pWX1023 DNA into CA-2 embryos. When each animal was assayed at the third larval instar, a portion of nonsalivary gland tissue was tested for $A d h^{s}$ activity on cellulose acetate gels to verify the presence of injected DNA. RNA from the remaining nonsalivary gland tissues and from the salivary glands was extracted, fractionated on agarose gels, and probed for Sgs-5 RNA.

Twelve animals transformed with paDm2459 were positive for Sgs-5 RNA in salivary glands, and all were negative for $S g s-5$ expression in nonsalivary gland tissues. Eleven salivary gland samples from individuals injected with paDm 498 contained $S g s-5$ RNA, whereas none of the corresponding nonsalivary gland RNA prepa-

Table 1. Expression of injected Sgs-5 genes in salivary glands

\begin{tabular}{|c|c|c|c|c|}
\hline \multirow[b]{2}{*}{$\mathrm{DNA}^{\mathrm{a}}$} & \multicolumn{2}{|c|}{$\begin{array}{l}\text { Insert fragment } \\
\text { boundaries }\end{array}$} & \multirow{2}{*}{$\begin{array}{c}\mathrm{RNA}^{+\mathrm{d}} \\
(\%)\end{array}$} & \\
\hline & $5^{\prime b}$ & $3^{\prime c}$ & & \\
\hline \multicolumn{5}{|c|}{ Oregon- $\mathrm{R}$} \\
\hline 2459 & $\sim 2400$ & $\sim 500$ & 95 & $(21 / 22)$ \\
\hline 494 & $\sim 2400$ & $\sim 500$ & 89 & (17/19) \\
\hline 1687 & 173 & 69 & 92 & $(12 / 13)$ \\
\hline 500 & 173 & 69 & 90 & $(9 / 10)$ \\
\hline 498 & 109 & 69 & 97 & $(28 / 29)$ \\
\hline 495 & 61 & 69 & 0 & $\{0 / 41\}$ \\
\hline \multicolumn{5}{|l|}{ CA-2 } \\
\hline 87 & 173 & 69 & 0 & $|0 / 33|$ \\
\hline
\end{tabular}

${ }^{a}$ The $S g s-5$-containing plasmids injected into embryos (Fig. 1A). The source of the insert DNA is indicated: CA-2 DNA for pfDm87; Oregon-R DNA for all others. All injections were into CA-2 embryos.

b The number of base pairs upstream from the RNA start site.

c The number of base pairs downstream from the end of the RNA coding region.

d The number of assayed animals that expressed $S g s-5$ RNA (Fig. 2A). The percentage of $S g s-5^{+}$animals for each series was calculated as:

$$
\frac{S g s-5 \mathrm{RNA}^{+} \text {animals }}{\text { Animals assayed }- \text { animals excluded }} \times 100 .
$$

Assayed animals were excluded from further consideration due to either improper developmental stage, based on Sgs-3 expression (Fig. 2B), or lack of evidence for injected DNA, based on $\mathrm{ADH}$ activity or the absence of injected plasmid DNA /see Materials and methods). 


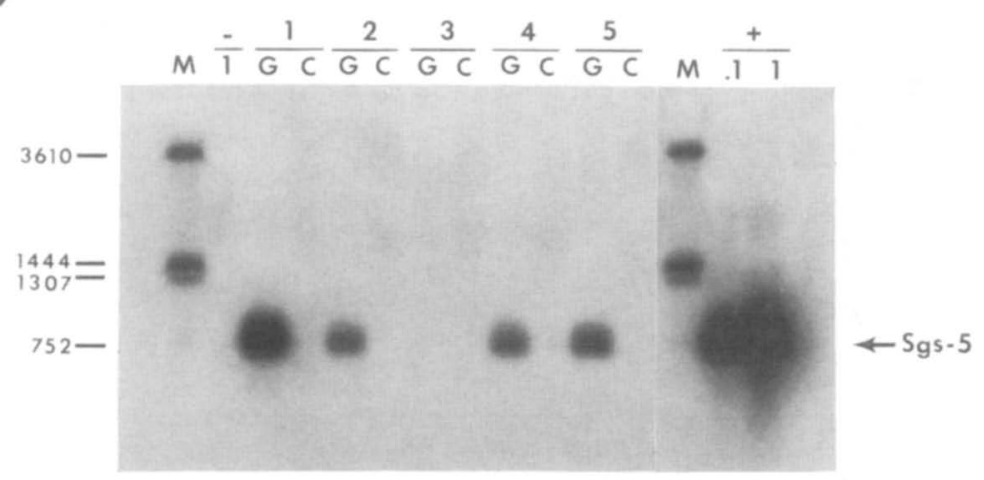

\section{B. 498}

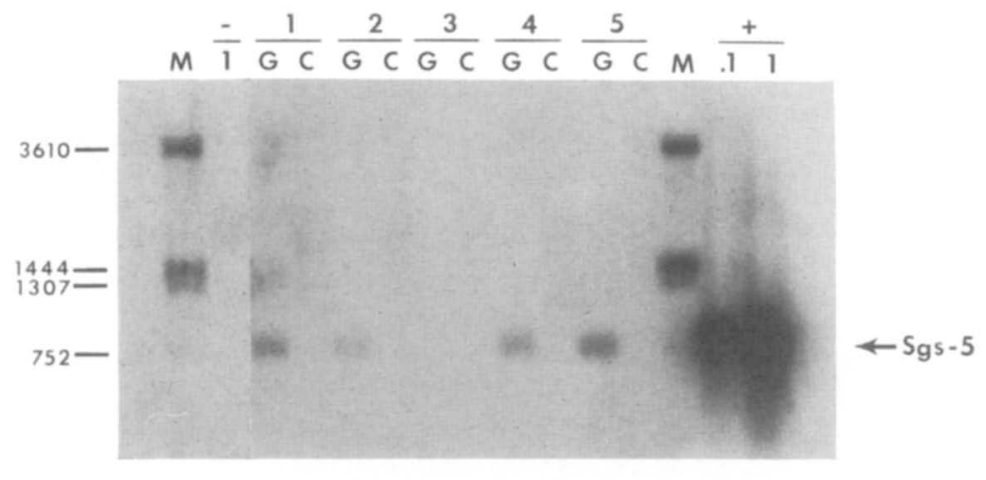

Figure 3. Tissue specificity. Embryos injected with either paDm2459 $(A)$ or paDm498 $(B)$ were recovered as third-instar larvae and dissected to separate salivary gland $(G)$ from nonsalivary (or carcass, $C$ ) tissues. RNA was extracted from the tissues, fractionated through formaldehyde gels, blotted to nitrocellulose, and probed for Sgs-5 RNA with ${ }^{32} \mathrm{P}$-labeled single-stranded RNA synthesized from pnDm384. Control lanes contain RNAs from 1 larval equivalent of stock CA-2 $(-)$, the non-Sgs-5expressing stock used as the source of host embryos for transformation, and 1 and 0.1 larval equivalents from Oregon-R $(+1$, the Sgs-5 RNA-expressing standard stock. Lanes with size markers /single-stranded DNA fragments generated by restriction endonuclease cleavage of pBR322 with either EcoRI-PstI or TaqI) are labeled $M$. For each injected plasmid, the results from five of the animals tested are shown as gland/carcass pairs $(1-5)$. rations showed detectable amounts of the Sgs-5 RNA (examples are shown in Fig. 3). These results indicate that the information required to express $S g s-5$ in third instar salivary glands occurs close to the RNA coding region, within 109 bp upstream and 69 bp downstream.

\section{Analysis of an Sgs-5 RNA null allele}

The Drosophila melanogaster stock CA-2 accumulates no detectable Sgs-5 RNA in third instar larvae (or at any other stage of development), but does contain a copy of the Sgs-5 gene as evidenced by in situ hybridization to polytene chromosomes and by DNA blot analysis of genomic DNA (Guild and Shore 1984).

Stuctural analysis of the CA-2 Sgs-5 allele. The CA-1 and CA-2 fly stocks are closely related, both having been established from the same captured fly population, but unlike CA-2, the Sgs-5 gene is actively transcribed in CA-1 larvae at a level similar to that found in Oregon- $R$ (Guild and Shore 1984). A physical map of the Sgs-5 region was determined for each of the three stocks, using DNA isolated from adult flies and mapping with restriction endonucleases by standard methods. Within the region examined $(10 \mathrm{~kb}$ upstream to $8 \mathrm{~kb}$ downstream from the Sgs-5 structural gene), the CA-2 restriction map is nearly identical to the maps of CA-1 and OregonR DNA (data not shown). The Sgs-5 alleles of Oregon-5 and CA-1 were observed to differ from the CA-2 null allele at restriction sites approximately 4.6 and $7.9 \mathrm{~kb}$ upstream from the $S g s-5$ RNA coding region. It is possible that the DNA regions marked by these sites may be associated with the regulation of $S g s-5$ expression.

Genetic analysis. To evaluate whether the CA-2 Sgs-5 null phenotype is linked to the $S g s-5$ structural gene, we mapped the DNA element responsible for this phenotype onto the Drosophila genetic map. The Sgs-5 structural gene resides between the third chromosome marker loci red (3-53.6) and ebony (3-70.7). An initial set of experiments demonstrated that the CA- 2 null phenotype segregates with the red-ebony region, and further analysis has shown that the DNA region responsible for the null phenotype is located between these markers at 3-60.4. This genetic map position is consistent with the cytogenetic position of the $S g s-5$ structural gene at 90B3-8 on the polytene chromosome map relative to the cytogenetic positions of red (88A-C) and ebony (93B7-F9) (Lindsley and Grell 1968). These data indicate that the CA-2 Sgs-5 RNA- phenotype is located in the Sgs-5 structural gene or in a nearby region.

Somatic transformation. The transformation experiments described above using segments of the Sgs-5 gene region derived from the Oregon- $\mathrm{R}$ genome have shown that a 1012-bp HindIII fragment includes all the information required for regulated expression. The corresponding DNA segment (pfDm87; Fig. 1A) from the CA-2 stock was tested for its ability to express the $S g s-5$ gene. CA-2 embryos were coinjected with DNA from pfDm87 and pWX1023, allowed to develop to the third larval instar, and assayed for Sgs-5 transcripts.

Figure 4A shows salivary gland RNAs from 14 of the 
Figure 4. Examples of $S g s-5$ RNA and plasmid DNA in injected animals. Embryos injected with plasmids containing the Sgs-5 ${ }^{\text {CA2 }}$ allele (pfDm87) and the Drosophila $A d h^{s}$ gene (pWX1023) were assayed after developing to the third larval instar. (A) Third larval instar salivary glands were isolated and RNA extracted. The RNAs (lanes 1-14) were denatured with formaldehyde, fractionated through a $1.4 \%$ (wt/vol) agarose/formaldehyde gel, blotted to nitrocellulose, and probed for Sgs-5 transcripts with 32P-labeled pnDm384 RNA. The filter was exposed to Kodak XAR-5 X-ray film for 5 days with an intensifying screen. Control lanes show the Sgs-5 RNA signals for uninjected animals: CA-2 $(-1,1$ larval equivalent of RNA, and Oregon- $R(+), 0.1$ or 0.5 larval equivalents of RNA. Lanes labeled $M$ contain fractionated single-stranded DNA length standards generated by EcoRI-PstI and TaqI digests of pBR322. Only some of the marker fragments hybridize with the riboprobe preparation used to probe this blot. The light hybridization signals seen in all larval RNA samples at about $1.8 \mathrm{~kb}$ represents nonspecific binding of the riboprobe to rRNA. The filter was reprobed for endogenous $S g s$-3 transcripts with nick-translated aDm2023 DNA (data not shown). (B) DNA was isolated from nonsalivary gland tissues of the injected animals described in $A$. The DNAs were digested with the restriction endonuclease SphI, fractionated through a 0.7 (wt/vol) agarose gel, and probed for the presence of the $S g s-5$ gene with ${ }^{32}$ P-labeled pnDm384 RNA. The position of the endogenous Sgs-5 genomic gene copy is indicated (g). The main hybridization signal to plasmid DNA $(\mathrm{p})$ is to linear pfDm87 DNA (middle plasmid band); undigested nicked and supercoiled pfDm87 DNAs are indicated above and below the linear band.

injected individuals. No detectable $S g s-5$ transcripts are observed. Thirteen of the 14 corresponding DNA samples contain injected pfDm87 plasmid DNA (Fig. 4B). Of a total of 42 animals analyzed for Sgs-5 transcripts, 33 were in the proper developmental stage and contained injected DNA; none of these animals directed the accumulation of $S g s-5$ transcripts (Table 1). The results indicate that the inability of the $S g s-5^{C A 2}$ allele to transcribe is due to a feature of the DNA sequences within the 1012-bp HindIII restriction fragment.

The DNA sequence of the Sgs-5 ${ }^{\mathrm{CA} 2}$ allele. The DNA sequence of the 1012-bp HindIII fragment of CA-2 genomic DNA has been determined using both MaxamGilbert chemical degradation and Sanger dideoxy chaintermination methods. The corresponding restriction fragment from the Oregon- $\mathrm{R}$ stock contains the entire Sgs-5 RNA coding region and also has been analyzed by DNA sequencing (Shore and Guild 1986).

The CA-2-derived sequence is nearly identical to that from the Oregon-R genome: Only seven single-base-pair substitutions are observed. Figure 1B shows a portion of the determined sequence (through the end of exon 1) with the seven substitutions indicated. Four of the substitutions occur in the protein coding region, all within the first exon. Three of these changes would alter the predicted amino acid sequence (if a protein was translated from the CA-2 gene copyl: at +84 bp CAC (His) $\rightarrow$ CAA (Gln); at +154 bp ATA (Ile) $\rightarrow$ GTA (Val); at +175 bp CCA (Pro) $\rightarrow$ TCA (Ser). The fourth substi- tution conserves the amino acid: at +63 bp TTA (Leu) $\rightarrow$ TTG (Leu). The other three base pair substitutions occur upstream from the RNA start site: $A \rightarrow G$ at $-7 \mathrm{bp}, \mathrm{G} \rightarrow \mathrm{A}$ at $-65 \mathrm{bp}$, and $\mathrm{G} \rightarrow \mathrm{A}$ at $-84 \mathrm{bp}$.

\section{Discussion}

The boundaries of the cis-acting sequences required for Sgs-5 expression have been determined by somatic transformation: A segment of genomic DNA containing the Sgs-5 coding region, $109 \mathrm{bp}$ upstream, and $69 \mathrm{bp}$ downstream includes the information required for $S g s-5$ transcription in third-instar salivary glands. Sequences essential for Sgs-5 activity occur between 61 and $109 \mathrm{bp}$ $5^{\prime}$ to the RNA start site; removal of these sequences is correlated with the loss, or at least the severe reduction, of expression. These results locate important regulatory elements of Sgs-5 very close to the coding region of the gene.

Since each injected animal can be assayed only at a single time point during development, it is not possible to analyze expression of the injected $S g s-5$ gene through a series of developmental stages derived from a single injection event. Therefore, the data cannot be used to conclude that transformed animals express $S g s-5$ solely in third-instar salivary glands. The possibility remains that expression occurs in salivary glands or nonsalivary gland tissue at earlier or later stages. However, we have some indication that the injected DNA segments are 
regulated in a stage-specific manner, or at least that they are not constitutively expressed. Over the course of these experiments we have noted individuals containing injected DNA (in expressible constructions) that show no or low levels of Sgs-3 RNA ( $\mathrm{n}=14$ ), and therefore must have been assayed earlier or later during development than the $S g s$ gene expression period, also are not observed to synthesize Sgs-5 RNA.

Regions more distal to the coding region also may influence $S g s-5$ transcription. The somatic transformation experiments do not control for the number of $S g s-5$ gene copies introduced into an animal by injection; it is therefore difficult to associate a given segment of DNA with increased or reduced gene expression. However, estimation of Sgs-5 RNA levels directed by different constructs (Fig. 2) indicates that RNA levels directed by the $3.7-\mathrm{kb}$ BamHI restriction fragment /contained in plasmids ppDm494 and paDm2459) can occur at higher levels than those directed by the $1.0-\mathrm{kb}$ HindIII fragment (paDm1687 and paDm500). This suggests that an additional cis-acting element controlling the level of regulated $S g s-5$ transcription maps to the region bounded by the upstream BamHI site $(\sim-2400 \mathrm{bp})$ and the HindIII site $(-173 \mathrm{bp})$.

The D. melanogaster stock CA-2 directs no detectable accumulation of Sgs-5 transcripts (Guild and Shore 1984). Genetic analysis shows that this null phenotype maps at or near the site of the $S g s-5$ structural gene, indicating that the lack of $S g s-5$ activity is not due to an alteration of a distant genetic locus that is required for the expression of Sgs-5. This hypothesis has been confirmed by embryo transformation experiments. The Sgs-5 gene from a normally Sgs-5-transcribing stock /Oregon- $\mathrm{R}$ ) is transcriptionally active when assayed in CA-2 salivary glands. Therefore, CA-2 salivary gland cells possess all the necessary $S g s-5$ transcription factors. When the corresponding segment from the CA-2 genome (contained in pfDm87; Table 1) is tested in the transformation assay, no Sgs-5 transcripts are detected, demonstrating that information required for expression nscurs in the Oregon- $R$ segment but is absent from the CA-2 segment. The results also indicate that the CA- 2 phenotype is not caused by a trans-acting negative factor that is present in CA-2 salivary gland cells.

Comparison of the two Sgs-5 alleles, one that actively transcribes and accumulates $S g s-5$ RNA (from Oregon-R) and one that does not (from CA-2), by DNA sequencing and expression in the somatic transformation assay, has shown that one or a combination of seven single-basepair substitutions between 84 bp upstream and 175 bp downstream from the RNA start site must be responsible for the absence of Sgs-5 RNA from the null allele. Any one or a combination of these sites could contribute to the apparent transcriptional inactivity of the Sgs-5 CA2 allele. Two of the CA-2 base substitutions, at -84 and $-65 \mathrm{bp}$, are of particular interest since they occur within a region that appears essential for Sgs-5 expression $(-61$ to $-109 \mathrm{bp})$. Both sites occur in the vicinity of the identified CAAT sequence element (Fig. 1B). Point mutations within the CAAT sequence have been observed to affect the level of transcription, some alter- ations enhancing, while others reducing, expression in other eukaryotic genes (Gelinas et al. 1985; Collins et al. 1985; Graves et al. 1986).

DNA regions required for the expression of other members of the coordinately regulated intermolt gene set have been examined by $P$ element-mediated germ line transformation. Closely linked elements are required for the tissue-specific expression of $\mathrm{Sgs}-3$ and Sgs-4 (Richards et al. 1983; Crowley et al. 1984; Bourouis and Richards 1985; Meyerowitz et al. 1985; McNabb and Beckendorf 1986; Vijay Raghavan et al. 1986; Shermoen et al. 1987). Like Sgs-5, Sgs-3 apparently possesses all essential transcriptional information very close to (within 130 bp upstream) its coding region (Meyerowitz et al. 1985; Vijay Raghaven et al. 1986) whereas Sgs-4 appears to require information between 392 and 568 bp upstream of the RNA start site (McNabb and Beckendorf 1986; Shermoen et al. 1987). Thus, functionally similar cis-acting controlling elements have been identified and are linked to the $5^{\prime}$ ends of the salivary gland secretion genes in Drosophila. Whether these elements have any structural similarities at the nucleotide sequence level awaits further experiments.

\section{Materials and methods}

\section{Materials}

Restriction endonucleases, ClaI linkers (dCATCGATG), T4 DNA ligase, polynucleotide kinase, E. coli DNA polymerase I and Klenow fragment (New England Biolabs), nitrocellulose, NA-45 membrane, Elutip-d columns (Schleicher and Schuell), reagents for the production in vitro of SP6-promoted transcripts (Promega Biotec), and $\left[\gamma^{-32} \mathrm{P}\right]-$ and $\left[\alpha^{-32} \mathrm{P}\right]$ deoxyribonucleoside triphosphates (Amersham) were purchased from the indicated sources. Components of the cellulose-acetate gel system were obtained from Helena Laboratories. $\mathrm{ADH}$ staining solution contained NAD (Boehringer-Mannheim or Chemical Dynamics Corp.), 2-butanol (Aldrich, gold label), nitro blue tetrazolium (Grade III), and 2-methoxy phenazine methosulfate (Sigma). Calf alkaline phosphatase and sheared salmon sperm DNA carrier were prepared as described (Guild 1984). Needles for injections were pulled from $1-\mathrm{mm}$ thin-wall Kwik-Fil capillaries with a filament (W-P Instruments, Inc.). Halocarbon oil, series 700 (Halocarbon Products Corp.), E. coli tRNA (BoehringerMannheim), low-gelling-temperature agarose (FMC-Marine Colloids), formamide (Matheson, Coleman and Bell), and XAR-5 X-ray film (Kodak) were purchased from the indicated sources.

\section{Drosophila stocks}

The D. melanogaster stock Oregon-R was originally obtained from the Department of Biochemistry (Stanford University School of Medicine). CA-1 and CA-2 were obtained from the stock collection at Cornell University. These two stocks were established by B. Wallace in 1954 from the same captured fly population (collected by D.J. Nolte, University of Witwatersrand) originating in the Stellenbosch region near Cape Town, South Africa (B. Wallace, Virginia Polytechnical Institute, pers. comm.). The third chromosome marker stock mwh red $e$ was received from A. Shearn (Johns Hopkins University).

All stocks were maintained at $18^{\circ} \mathrm{C}$ or $25^{\circ} \mathrm{C}$ on standard corn flour-agar medium (Elgin and Miller 1978) supplemented with live yeast. 


\section{Genetic mapping}

These genetic experiments were done to test the hypothesis that the CA-2 Sgs-5 null phenotype is associated with the $S g s-5$ structural gene region. The red (88A-C) and ebony (93B7-F9) loci are located (Lindsley and Grell 1968) to either side of the Sgs-5 structural gene cytological locus, 90B3-8 (Guild and Shore 1984).

The experiment was designed as a standard three-point cross, complicated by the fact that $S g s-5$ expression has no visible phenotype but is monitored by probing for the presence of Sgs-5 RNA during the third larval instar. Therefore, progeny of a given cross could not be assayed directly for Sgs-5 expression (since doing so would prevent the animal from producing the following generation); instead, the individuals in question were test-crossed, and the offspring assayed for the presence of $S g s-5$ RNA to reveal the allele carried by the parent.

The initial cross (CA- $2 \times m w h$ red e) and backcross $(\mathrm{F} 1 \times$ mwh red $e)$ confirmed the genetic distance between the red and ebony loci and provided animals in which the red or ebony locus had recombined with the $S g s-5^{C A 2}$ null allele. These recombinations (male progeny were selected) were used in test-crosses (with CA-2) to reveal the recombination frequencies between the red and ebony loci and the CA-2 Sgs-5 null phenotype. Test-cross progeny were analyzed for Sgs-5 RNA by extracting RNA from four or five third instar larvae per test-cross. The RNA from each individual was treated with DNase, denatured and applied to nitrocellulose in a dot blot apparatus, and then probed for Sgs-5 RNA. The probability of drawing the correct conclusion from a given cross is 0.94 if four progeny per cross are tested and 0.97 if five progeny are tested.

\section{Cloned DNA segments}

All Sgs-5-containing subclones containing $S g s-5^{O R}$ sequences are derivatives of cloned genomic DNA segments obtained from an Oregon-R DNA library (Guild 1984), either from $\lambda \mathrm{Dm} 83$ (ppDm494) or from $\lambda \mathrm{bDm} 1508$ (all other subclones). Clone $\lambda \mathrm{bDm} 83$ contains $S g s-5$ haplotype A DNA and $\lambda$ bDm 1508 contains DNA from haplotype $B$; both haplotypes can transcribe $S g s-5$ (Shore and Guild 1986).

The plasmid ppDm494 contains the $3.7-\mathrm{kb}$ BamHI fragment that includes the Sgs-5 gene inserted into the ClaI site of the polylinker in the plasmid pPA-2. This plasmid was constructed by J. Posakony (University of California, San Diego) and contains a Drosophila P element, an $\mathrm{XbaI}$ fragment containing the Drosophila $A d h$ gene, and pUC-9 sequences. A diagram of pPA-1 (identical to pPA-2 but with the $X b a I$ insert in the reverse orientation) can be found in Zehring et al. (1984). Bacteriophage $\lambda \mathrm{bDm} 83 \mathrm{DNA}$ was cut with $\mathrm{BamHI}$, then ethanol-precipitated. The DNA ends were filled in with DNA polymerase I Klenow fragment, and ClaI linkers were added by blunt-end ligation with T4 DNA ligase. The DNA was redigested with ClaI (no ClaI sites occur within the insert fragment), and the specific DNA fragment was recovered from a $0.7 \%$ low-melt agarose gel by electrophoresing the fragment onto NA-45 membrane. After washing the membrane in $150 \mathrm{~mm} \mathrm{NaCl}$ in TE8 $110 \mathrm{~mm}$ Tris- $\mathrm{HCl} \mathrm{pH} 8,1 \mathrm{~mm}$ EDTA), the DNA was recovered by eluting with $200 \mu \mathrm{l}$ of $1 \mathrm{M} \mathrm{NaCl}$ in TE8 at $65^{\circ} \mathrm{C}$ for $1 \mathrm{hr}$, then in fresh elution solution for $15 \mathrm{~min}$ at $65^{\circ} \mathrm{C}$, followed by ethanol precipitation. The insert fragment was ligated to ClaI-digested and phosphatased pPA-2 DNA with T4 DNA ligase at $15^{\circ} \mathrm{C}$ overnight. Ligated DNA was transformed into E. coli $\mathrm{HB101}$ cells (Boyer and Roulland-Dussoix 1969) by standard methods. Transformed cells were screened by colony hybridization, probing with nick-translated DNA from the $1-\mathrm{kb}$ HindIII insert of paDm 1687. (Unless indicated, procedures are modifications of those found in Maniatis et al. 1982).
The subcloning of paDml687 has been described /Guild 1984). The recovery of the $3.7-\mathrm{kb}$ BamHI fragment from $\lambda \mathrm{bDm} 1508$ into the plasmid vector pBR322 to construct paDm2459 was accomplished by similar methods. The 1012-bp HindIII fragment insert of paDml687 was reoriented to form paDm500: Plasmid paDml687 DNA was digested with the restriction endonuclease HindIII, then religated in the presence of T4 DNA ligase.

The plasmids paDm498 and paDm495 were derived from paDm 1687 by digesting paDml687 DNA with either RsaI (paDm498) or HaeII (paDm495). HaeII-cut DNA was treated with DNA polymerase I Klenow fragment $\left(22^{\circ} \mathrm{C}, 15 \mathrm{~min}\right)$ in the presence of all four deoxyribonucleoside triphosphates $(20 \mu \mathrm{M}$ each). These steps linearized the DNA and provided blunt ends. After phenol extraction and ethanol precipitation, the DNAs were digested with HindIII and fractionated through a $0.7 \%$ (wt/vol) low-melt agarose minigel. Ethidium bromide-stained DNA fragments were visualized by long-wave ultraviolet light. Gel slices containing the HaeII-HindIII (900 bp) and the RsaIHindIII $(948 \mathrm{bp})$ fragments were cut from the gel, placed in 500 $\mu l$ of buffer $[0.2 \mathrm{M} \mathrm{NaCl}, 20 \mathrm{~mm}$ Tris- $\mathrm{HCl}(\mathrm{pH} 7.5), 1 \mathrm{~mm}$ EDTA $)$, melted at $65^{\circ} \mathrm{C}(5 \mathrm{~min})$, then phenol-extracted. The aqueous phase was run through an Elutip-d column, and the DNA was recovered following the recommended procedure (Schleicher and Schuell). Following ethanol precipitation, the recovered insert fragments were ligated to pBR322 DNA that had been cut with the restriction enzyme ClaI to linearize the plasmid, filled in with Klenow fragment, cut with HindIII, and treated with calf alkaline phosphatase (Guild 1984). Ligated DNAs were transformed into E. coli HB101 cells, selected for ampicillin resistance and tetracycline sensitivity, and screened by hybridization as described above.

The constructions meDm39 and pnDm384 contain Oregon-R genomic sequences corresponding to the HindIII fragment that includes the Sgs-5 RNA coding region (the same insert that occurs in paDm1687) inserted M13mp8 and pGEM-1 vectors, respectively (Shore and Guild 1986).

The CA-2 Sgs-5 allele and adjacent sequences were recovered from a library of CA-2 genomic DNA HindIII fragments cloned into the $\lambda$ Charon 30 vector (Rimm et al. 1980). The phage vector isolate we used apparently had suffered an internal deletion that resulted in the removal of one (of the two) HindIII cleavage sites. Vector DNA was prepared by sealing the annealed cohesive ends with bacteriophage T4 ligase (Davis et al. $1980)$, digesting the DNA to completion with HindIII $(0.5 \mathrm{U} / \mu \mathrm{g}$, $\left.37^{\circ} \mathrm{C}, 2 \mathrm{hr}\right\rangle$, and treating it with calf alkaline phosphatase $\{200$ $\left.\mathrm{U} / \mu \mathrm{g}, 37^{\circ} \mathrm{C}, 1 \mathrm{hr}\right)$. CA-2 embryonic DNA was digested to completion with $\mathrm{HindIII}\left(2.5 \mathrm{U} / \mu \mathrm{g}, 65^{\circ} \mathrm{C}, 1 \mathrm{hr}\right)$ and combined with the prepared vector DNA at a ratio of $1: 1$ or $1: 4(\mathrm{wt} / \mathrm{wt})$. The DNA mixtures (final concentration $=100 \mu \mathrm{g} / \mathrm{ml}$ ) were ligated with T4 DNA ligase at $12^{\circ} \mathrm{C}$ for $15 \mathrm{hr}$. The recombinant DNA was packaged into bacteriophage particles exactly as described by Hohn (1979) and transduced into E. coli K802 cells (Wood 1966).

The 1012-bp HindIII fragment corresponding to the genomic DNA segment of the Oregon-R stock that contains the $S g s-5$ RNA coding region was recovered from this library ( $\lambda \mathrm{dDm} 26)$. This HindIII fragment was subcloned (pfDm87) into the HindIII site of the plasmid vector, $\mathrm{pBR}^{-\mathrm{S}}$, a derivative of $\mathrm{pBR} 322$. The plasmid $\mathrm{pBR}^{-} \mathrm{S}$, a gift of N. Kallenbach (University of Pennsylvania), is identical to pBR322 except that it contains a 21 -bp deletion that removes the unique Sall site.

The plasmid pWX1023 was provided by P. Martin (Waksman Institute, Rutgers University). The 4.7-kb EcoRI fragment that includes the gene for the Drosophila alcohol dehydrogenase slow allele $\left(A d h^{S}\right)$ derived from the Canton-S fly stock was cloned into the EcoRI site of pUC-18. This restriction fragment 
contains the sequences necessary to express the $A d h$ gene (Posakony et al. 1985; Martin et al. 1986).

The plasmid aDm2023 was a gift from E. Meyerowitz /California Institute of Technology). This construct consists of a 2.4-kb SalI fragment containing the Sgs-3 gene inserted into the pBR322 SalI site (Garfinkel et al. 1983).

\section{Preparation and analysis of nucleic acids}

RNA was extracted from whole larvae (Guild 1984) or from hand-dissected larval salivary glands or carcasses (Shore and Guild 1986). Following ethanol precipitation, the RNA was fractionated through $1.4 \%$ (wt/vol) agarose gels containing formaldehyde (Lehrach et al. 1977) and blotted to nitrocellulose (Thomas 1983). Single-stranded, restriction endonuclease-digested pBR322 DNAs were used as length standards (Guild 1984).

The procedures used for DNA isolation, fractionation, and blotting (Guild 1984; Shore and Guild 1986) and for DNA sequence analysis (Shore and Guild 1986) are described in the indicated references.

\section{DNA labeling and hybridization}

SP6-promoted synthesis from pnDm384 produces RNA complimentary to the Sgs-5 RNA. In vitro transcription reactions using linear templates (previously cleaved with BamHI) and SP6 RNA polymerase were performed as described by Melton et al. (1984) using $\left[\alpha^{-32} \mathrm{P}\right] \mathrm{CTP}(400 \mathrm{Ci} / \mathrm{mmole})$ at a concentration of $6.25 \mu \mathrm{M}$.

Following transfer to nitrocellulose, RNA blots were baked under vacuum at $80^{\circ} \mathrm{C}$ for $90 \mathrm{~min}$. Filters were pretreated about $5 \mathrm{hr}$ at $37^{\circ} \mathrm{C}$ in $50 \%$ (vol/vol) deionized formamide, $5 \times$ SSPE $\left(\mathrm{I} \times \mathrm{SSPE}\right.$ is $0.18 \mathrm{M} \mathrm{NaCl}, 6.7 \mathrm{mM} \mathrm{NaH} \mathrm{PO}_{4}, 6.7 \mathrm{mM} \mathrm{Na}_{2} \mathrm{HPO}_{4}$, 1 mM EDTA, pH 6.8), 10\% sodium dextran sulfate, $1 \times$ Denhardt's solution (Denhardt 1966), 1.0\% (wt/vol) sodium dodecyl sulfate, denatured salmon sperm DNA $(250 \mu \mathrm{g} / \mathrm{ml})$, and E. coli tRNA $(100 \mu \mathrm{g} / \mathrm{ml})$, then hybridized by adding $1 \times 10^{6} \mathrm{cpm} / \mathrm{ml}$ of ${ }^{32} \mathrm{P}$-labeled pnDm384 RNA transcripts and incubating at $65^{\circ} \mathrm{C}$ overnight. Filters were washed in $0.2 \times$ SSPE, $0.1 \%$ sodium dodecyl sulfate at $70^{\circ} \mathrm{C}(1 \mathrm{hr}, 4$ changes $)$, then exposed to Kodak XAR-5 X-ray film with an intensifying screen.

To remove hybridized probe, the filters were washed [in $25 \%$ (vol/vol) formamide; $0.1 \%$ (vol/vol) sodium dodecyl sulfate, 1 $\mathrm{mM}$ EDTA] first at $100^{\circ} \mathrm{C}(2 \times 5 \mathrm{~min})$, then at room temperature $(1 \times 5 \mathrm{~min})$. To reprobe, the filters were pretreated as above. For hybridization, $2.5 \times 10^{5} \mathrm{cpm} / \mathrm{ml}$ of denatured $\mathrm{aDm} 2023$ that had been labeled by nick-translation (Rigby et al. 1977) as described (Shore and Guild 1986) was added to the filter. Washing was done as above, but at $65^{\circ} \mathrm{C}$.

\section{ADH protein preparation and analysis}

An individual larva, adult fly, or tissue sample was homogenized in a $1.5-\mathrm{ml}$ microfuge tube in $10 \mu l$ homogenization buffer (Helena Laboratories' Supre heme buffer with $1 \%$ Triton $\mathrm{X}-100$ ) on ice. Debris was pelletted in a microfuge for $30 \mathrm{sec}$; this step was omitted when a small tissue sample was being extracted. The samples were applied to cellulose acetate Titan III-H plates as recommended by the Helena Laboratories "Super $Z^{\prime \prime}$ system. Electrophoresis was performed in a Pharmacia flatbed apparatus (precooled to $4^{\circ} \mathrm{C}$ ) at $400 \mathrm{~V}$ for $90 \mathrm{~min}$. ADH protein staining was accomplished by combining the staining solution $5 \mathrm{ml}$ of $5 \mathrm{mg} / \mathrm{ml}$ nitro blue tetrazolium, $1 \mathrm{ml}$ of 50 $\mathrm{mg} / \mathrm{ml} \mathrm{NAD}, 0.5 \mathrm{ml}$ of 2 -methoxyl phenazine methosulfate, 1 $\mathrm{ml}$ of 2 - butanol, $1 \mathrm{ml}$ of $1 \mathrm{M}$ Tris $\mathrm{HCl}, \mathrm{pH} 8,20 \mathrm{ml}$ Supre heme buffer) with $20 \mathrm{ml}$ of $1 \%$ agarose that had been heated to boiling. The mixture was poured into a large petri dish $(150$ $\mathrm{mm}$ ) and allowed to cool in the dark (nitro blue tetrazolium and 2-methoxy phenazine methosulfate are light sensitive). The electrophoresis gel was placed face down on the cooled agarose surface for $20-30 \mathrm{~min}$. To stop the staining reaction, the gel was placed in $5 \%$ acetic acid for 5 min with gentle agitation. The gel was rinsed in water, then air-dried.

The Helena Laboratories system was adapted for $\mathrm{ADH}$ staining by P. Martin in the lab of W. Sofer (Waksman Institute, Rutgers University).

\section{Somatic transformation}

(1) DNA preparation. Plasmid DNA preparations were made from bacterial cultures grown overnight in the presence of $50-100 \mu \mathrm{g} / \mathrm{ml}$ ampicillin with vigorous agitation in L broth, using a modification of the Triton X-100 method described by Davis et al. (1980) or a variation of that protocol that substitutes $10 \%$ (wt/vol) Sarkosyl for the Triton X-100 (P. Martin, pers. comm.). All DNAs used for embryo injections were prepared by banding in cesium chloride gradients (Davis et al. 1980). DNA was dissolved in injection buffer $(5 \mathrm{mM} \mathrm{KCl}, 0.1$ $\mathrm{mM}$ sodium phosphate buffer, $\mathrm{pH} 6.8 /$ at $500 \mu \mathrm{g} / \mathrm{ml}$. When two plasmids were coinjected into embryos, each plasmid was present at $500 \mu \mathrm{g} / \mathrm{ml}$ for a total DNA concentration of $1 \mathrm{mg} / \mathrm{ml}$. Unpublished data (P. Martin, N. Shen, G. Subrahmanyan, and W. Sofer, pers. comm.) examining the distribution of two coinjected plasmids within cells of injected animals have shown that increasing the concentration of injected DNA increases the percentage of cells receiving both plasmids. Using a total DNA concentration of $500 \mu \mathrm{g} / \mathrm{ml}$ (half the concentration used in these experiments) typically results in about $75 \%$ of $\mathrm{ADH}$ expressing cells receiving both plasmids.

(2) Embryo injections. The basic protocol used has been described by Martin et al. (1986). Embryos (10-20 min after laying) were collected, manually dechorionated, desiccated, and covered with halocarbon oil. DNA was injected into the anterior end of the embryo [to be in the vicinity of the salivary gland precursor nuclei (Demeric 1950)] at room temperature $\left(21-24^{\circ} \mathrm{C}\right)$. Injected embryos were placed in a humid chamber at $18^{\circ} \mathrm{C}$ for $40-48 \mathrm{hr}$; hatched larvae were removed from the oil into vials containing instant Drosophila medium (Carolina Biological Supply Co.) supplemented with live yeast. Animals were grown at $25^{\circ} \mathrm{C}$ to the third larval instar.

(3) Success of injections. The percentage of injected CA-2 embryos that hatched and developed to the third larval instar or later stages was variable from one injection experiment to the next. Overall, in experiments done to date, $19 \%$ of injected embryos developed to the third instar stage or later. An average of $38 \%$ of injected embryos hatched (range, $15-67 \%$ ) and $50 \%$ of those continued development (range, 20-74\%).

(4) RNA and ADH assays. At the third instar stage (4-5 days after hatching), animals were selected on the basis of size (close to wild-type third instar proportions) and behavior (actively climbing on a dry surface) and their salivary glands removed for RNA extraction. The morphology of each salivary gland was also noted upon dissection as an indication of the developmental stage. The remaining nonsalivary gland tissues were treated to recover RNA, ADH activity (as described above), and/or DNA (as described in Shore and Guild 1986).

(5) Data analysis. Table 1 shows a summary of the data for each injected plasmid. Some assayed individuals are eliminated from consideration as potential Sgs- 5 expressers because the controls either have shown that the assay has been done at a nonopitmal time for Sgs gene expression/determined by a lack of expression by the endogenous Sgs-3 gene) or that there is little or no evidence of injected DNA in the animal (determined 
by staining for $\mathrm{ADH}$ activity from the injected $A d h$ gene or by directly probing for the injected plasmid containing the $S g s-5$ gene copy). In these experiments, $24 \%(53 / 220)$ of the injected animals were excluded by these controls (range, 16-38\%). Although in the experiments in which expression is seen, a majority $(88-96 \%)$ of animals judged to be potential Sgs-5 expressers do express $S g s-5$, a few individuals (7/100) that are Sgs-5 RNA- cannot be explained by lack of injected DNA or improper developmental stage. Uneven distribution of injected DNA (e.g., low in salivary gland cells) could cause this result. In addition, scoring for Sgs-5 RNA signals on Northern blots was conservative: Any uncertainty, due to background levels on autoradiograms, for example, was considered a negative result. Therefore, "false negatives" may be included in this category.

Also worth noting are Sgs-5 RNA+ individuals that are Sgs-3 $\mathrm{RNA}^{-}(n=1)$, possibly due to sufficient injected DNA in the salivary glands to allow detection of expression at an unoptimal stage, or that are negative for injected ADH expression $(n=7)$, possibly due to uneven distribution of injected DNA as suggested above.

\section{Acknowledgments}

We thank Jim Posakony and Elliot Meyerowitz for sharing plasmid constructs, Neville Kallenbach for sharing his plasmid vector $\mathrm{pBR}-\mathrm{S}$, Bruce Wallace for information regarding the history of CA-1 and CA-2, Laurie Tompkins and Scott Poethig for helpful discussions on genetic crosses, Allen Shearn, Jim Fristrom, and Jim Posakony for gifts of fly stocks, Cecelia Lo and Stuart Kauffman for the generous use of microscopes and micromanipulators, Allen Place for assistance with $\mathrm{ADH}$ assays, and Lynn Faust for excellent technical assistance. We also thank Bill Sofer and Presley Martin for their invaluable help with the somatic transformation experiments and for sharing cloned DNAs, unpublished information, and their laboratory. E.S. is especially appreciative of the patience and encouragement given by P. Martin while teaching her embryo injection and $\mathrm{ADH}$ staining methods. This work was supported by a grant from the National Institutes of Health (5-RO1 GM28228).

\section{References}

Bourouis, M. and G. Richards. 1985. Remote regulatory sequences of the Drosophila glue gene sgs 3 as revealed by P-element transformation. Cell 40: 349-357.

Boyer, H.W. and D. Roulland-Dussoix. 1969. A complementation analysis of the restriction and modification of DNA in E. coli. J. Mol. Biol. 41: 459-472.

Collins, F.S., J.E. Metherall, M. Yamakawa, J. Pan, S.M. Weissman, and B.G. Forget. 1985. A point mutation in the ${ }^{A} \gamma$-globin gene promoter in Greek hereditary persistence of fetal haemoglobin. Nature 313: 325-326.

Crowley, T.E., P.H. Mathers, and E.M. Meyerowitz. 1984. A trans-acting regulatory product necessary for expression of the Drosophila melanogaster 68C glue gene cluster. Cell 39: $149-156$.

Davis, R.W., D. Botstein, and J.R. Roth. 1980. Advanced bacterial genetics. Cold Spring Harbor Laboratory, Cold Spring Harbor, New York.

Demerec, M. 1950. Biology of Drosophila. Wiley, New York.

Denhardt, D.T. 1966. A membrane-filter technique for the detection of complementary DNA. Biochem. Biophys. Res. Commun. 23: 641-646.

Elgin, S.C.R. and D.W. Miller. 1978. Mass rearing of flies and mass production and harvesting of embryos. In The genetics and biology of Drosophila (ed. M. Ashburner and T.R.F. Wright), vol. 2A, pp. 112-121. Academic Press, New York.
Fraenkel, G. and V.J. Brookes. 1953. The process by which the puparia of many species of flies become fixed to a substrate. Biol. Bull. 105: 442-449.

Garfinkel, M.D., R.E. Pruitt, and E.M. Meyerowitz. 1983. DNA sequences, gene regulation and modular protein evolution in the Drosophila $68 \mathrm{C}$ glue gene cluster. I. Mol. Biol. 168: $765-789$.

Gelinas, R., B. Endlich, C. Pfeiffer, M. Yagi, and G. Stamatoyannopoulos. 1985. G to A substitution in the distal CCAAT box of the ${ }^{A} \gamma$-globin gene in Greek hereditary persistance of fetal haemoglobin. Nature 313: 323-325.

Graves, B.J., P.F. Johnson, and S.L. McKnight. 1986. Homologous recognition of a promoter domain common to the MSV LTR and the HSV tk gene. Cell 44: 565-576.

Guild, G.M. 1984. Molecular analysis of a developmentally regulated gene which is expressed in the larval salivary gland of Drosophila. Dev. Biol. 102: 462-470.

Guild, G.M. and E.M. Shore. 1984. Larval salivary gland secretion proteins in Drosophila: Identification and characterization of the Sgs-5 structural gene. J. Mol. Biol. 179: 289-314.

Haenlin, M., H. Steller, V. Pirrotta, and E. Mohier. 1985. A 43 kilobase cosmid P transposon rescues the $f_{S}(1) K 10$ morphogenetic locus and three adjacent Drosophila developmental mutants. Cell 40: 827-837.

Hohn, B. 1979. In vitro packaging of $\lambda$ and cosmid DNA. Methods Enzymol. 68: 299-309.

Johnson, F.M. and C. Dennison. 1964. Genetic variation of alcohol dehydrogenase in Drosophila melanogaster. Nature 204: 906-907.

Lehrach, H., D. Diamond, J.M. Wozney, and H. Boedtker. 1977. RNA molecular weight determinations by gel electrophoresis under denaturing conditions, a critical reexamination. Biochemistry 16: 4743-4751.

Lindsley, D.L. and E.H. Grell. 1968. Genetic variations of Drosophila melanogaster. Carnegie Inst. Wash. Publ. 627.

Maniatis, T., E.F. Fritsch, and J. Sambrook. 1982. Molecular cloning: A laboratory manual. Cold Spring Harbor Laboratory, Cold Spring Harbor, New York.

Martin, P., A. Martin, A. Osmani, and W. Sofer. 1986. A transient expression assay for tissue-specific gene expression of alcohol dehydrogenase in Drosophila. Dev. Biol. 116: 574580.

McNabb, S.L. and S.K. Beckendorf. 1986. Cis-acting sequences which regulate expression of the $S g s-4$ glue protein gene of Drosophila. EMBO I. 5: 2331-2340.

Melton, D.A., P.A. Krieg, M.R. Rebagliati, T. Maniatis, K. Zinn, and M.R. Green. 1984. Efficient in vitro synthesis of biologically active RNA and RNA hybridization probes from plasmids containing a bacteriophage SP6 promoter. Nucleic Acids Res. 12: 7035-7056.

Meyerowitz, E.M. and D.S. Hogness. 1982. Molecular organization of a Drosophila puff site that responds to ecdysone. Cell 28: $165-176$.

Meyerowitz, E.M., M.A. Crosby, M.D. Garfinkel, C.H. Martin, P.H. Mathers, and K. Vijay Raghavan. 1985. The 68C glue puff of Drosophila. Cold Spring Harbor Symp. Quant. Biol. 50: $347-353$.

Muskavitch, M.A.T. and D.S. Hogness. 1980. Molecular analysis of a gene in a developmentally regulated puff of Drosophila melanogaster. Proc. Natl. Acad. Sci. 12: 7362-7366.

Posakony, J.W., J.A. Fischer, and T. Maniatis. 1985. Identification of DNA sequences required for the regulation of Drosophila alcohol dehydrogenase gene expression. Cold Spring Harbor Symp. Quant. Biol. 50: 515-520.

Preiss, A., U.B. Rosenberg, A. Kienlin, E. Seifert, and H. Jäckle. 1985. Molecular genetics of Krüppel, a gene required for segmentation of the Drosophila embyro. Nature 313: 27-32. 
Richards, G., A. Cassab, M. Bourouis, B. Jarry, and C. Dissous. 1983. The normal developmental regulation of a cloned sgs3 'glue' gene chromosomally integrated in Drosophila melanogaster by $\mathrm{P}$ element transformation. EMBO J. 2: 21372142.

Rigby, P.W.J., M. Dieckmann, C. Rhodes, and P. Berg. 1977. Labeling deoxyribonucleic acid to high specific activity in vitro by nick translation with DNA polymerase I. $I$. Mol. Biol. 113: 237-251.

Rimm, D.L., D. Horness, J. Kucera, and F.R. Blattner. 1980. Construction of coliphage lambda Charon vectors with BamHI cloning sites. Gene 12: 301-309.

Rubin, G.M. and A.C. Spradling. 1982. Genetic transformation of Drosophila with transposable element vectors. Science 218: $348-353$.

. 1983. Vectors for P-element-mediated gene transfer in Drosophila. Nucleic Acids Res. 11: 6341-6351.

Shermoen, A.W., J. Jongens, S.W. Barnett, K. Flynn, and S.K. Beckendorf. 1987. Developmental regulation by an enhancer from the Sgs-4 gene of Drosophila. EMBO I. 6: 207-214.

Shore, E.M. and G.M. Guild. 1986. Larval salivary gland secretion proteins in Drosophila: Structural analysis of the Sgs-5 gene. J. Mol. Biol. 190: 149-158.

Spradling, A.C. and G.M. Rubin. 1982. Transposition of cloned P elements into Drosophila germ line chromosomes. Science 218: 341-347.

Steller, H. and V. Pirrotta. 1984. Regulated expression of genes injected into early Drosophila embryos. EMBO J. 3: 165173.

Thomas, P.A. 1983. Hybridization of denatured RNA transferred or dotted to nitrocellulose paper. Methods Enzymol. 100: 255-266.

Ursprung, H., W. Sofer, and N. Burroughs. 1970. Ontogeny and tissue distribution of alcohol dehydrogenase in Drosophila melanogaster. Wilhelm Roux's Arch. Dev. Biol. 164: 201208.

Vijay Raghavan, K., M.A. Crosby, P.H. Mathers, and E.M. Meyerowitz. 1986. Sequences sufficient for correct regulation of Sgs-3 lie close to or within the gene. EMBO $J$. 5: 3321-3326.

Wolfner, M.F. 1980. "Ecdysone-responsive genes of the salivary glands of Drosophila melanogaster." Ph.D. thesis, Stanford University.

Wood, W.B. 1966. Host specificity of DNA produced by Escherichia coli: Bacterial mutations affected by the restriction and modification of DNA. J. Mol. Biol. 16: 118-133.

Zehring, W.A., D.A. Wheeler, P. Reddy, R.J. Konopka, C.P. Kyriacou, M. Rosbash, and J.C. Hall. 1984. P-element transformation with period locus DNA restores rhythmicity to mutant, arrhythmic Drosophila melanogaster. Cell 39: 369376. 


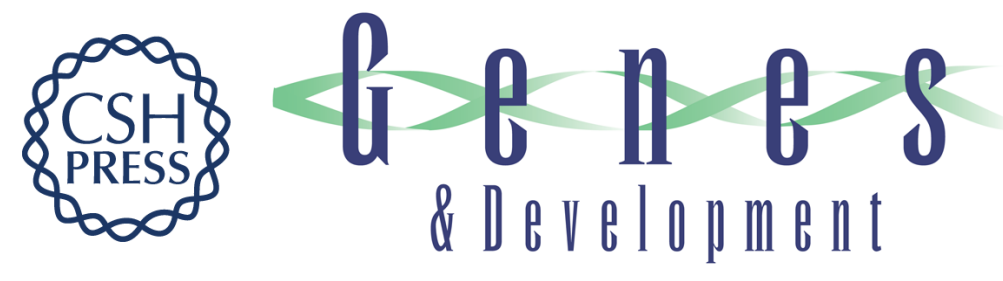

\section{Closely linked DNA elements control the expression of the Sgs-5 glue protein gene in Drosophila.}

E M Shore and G M Guild

Genes Dev. 1987, 1:

Access the most recent version at doi:10.1101/gad.1.8.829

References This article cites 37 articles, 4 of which can be accessed free at: http://genesdev.cshlp.org/content/1/8/829.full.html\#ref-list-1

License

Email Alerting

Receive free email alerts when new articles cite this article - sign up in the box at the top Service right corner of the article or click here.

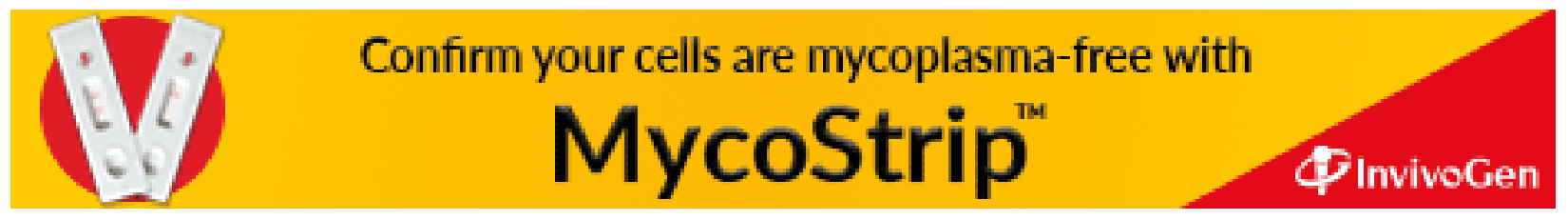

